\begin{tabular}{|c|c|}
\hline Title & Conversion of Technical Lignins to A mphiphilic Derivatives with High Surface A ctivity \\
\hline Author(s) & Homma, Harumi; Kubo, Satoshi; Y amada, T atsuhiko; Koda, Keiichi; Matsushita, Y asuyuki; U raki, Y asumitsu \\
\hline Citation & $\begin{array}{l}\text { Journal of W ood Chemistry and Technology, 30(2), 164-174 } \\
\text { https://doi.org/10.1080/02773810903349713 }\end{array}$ \\
\hline Issue Date & 2010-04 \\
\hline Doc URL & http:/hdl.handle.net/2115/45095 \\
\hline Rights & $\begin{array}{l}\text { This is an electronic version of an article published in Journal of Wood Chemistry and Technology, 30(2), A pril 2010, } \\
\text { 164-174. Journal of Wood Chemistry and Technology is available online at: } \\
\text { http://www.informaworld.com/openurl?genre=article\& issn=0277-3813\&volume=30\& issue=2\& spage=164 }\end{array}$ \\
\hline Type & article (author version) \\
\hline File Information & JWCT 30-2_164-174.pdf \\
\hline
\end{tabular}

Instructions for use 


\title{
Conversion of Technical Lignins to Amphiphilic Derivatives with High Surface Activity
}

\author{
Harumi Homma ${ }^{1)}$, Satoshi Kubo ${ }^{2)}$, Tatsuhiko Yamada ${ }^{2)}$, Keiichi Koda ${ }^{3)}$, \\ Yasuyuki Matsushita ${ }^{4)}$ and Yasumitsu Uraki ${ }^{3)}$
}

${ }^{1)}$ Graduate School of Agriculture, Hokkaido University, Sapporo 060-8589, Japan

${ }^{2)}$ Department of Biomass Chemistry, Forestry and Forest Products Research Institute, Tsukuba 305-8687, Japan

${ }^{3)}$ Research Faculty of Agriculture, Hokkaido University, Sapporo 060-8589, Japan

4) Graduate School of Bioagricultural Sciences, Nagoya University, Nagoya 464-8601, Japan 


\begin{abstract}
To make use of technical lignins as a nonionic polymeric surfactant, we have already reported the modification of acetic acid lignin (AL) to amphiphilic derivatives by polyoxyethylation using two types of polyethylene glycol (PEG) with diglycidyl (PEGDE) and monoglycidyl (EPEG) groups [1]. Kraft lignin (KL) was converted to amphiphiles in a similar manner. The resultant KL derivatives also indicated high surface activity.

Polyethylene glycol with long alkyl chain was introduced to AL, KL and lignosulfonate (LS) to prepare surfactants of high performance, using dodecyloxy-polyethylene glycol glycidyl ether (DAEO). The resultant DAEO-derivatives showed lower critical micelle concentration by 2-4 orders of magnitude than the corresponding PEGDE- and EPEG-derivatives. The DAEO-derivatives from LS showed better dispersibility for gypsum paste, one of cement components, than LS.
\end{abstract}

Keywords: Technical lignin, Surfactant, Surface activity, Dispersion 


\section{INTRODUCTION}

Woody biomass has been drawing much attention as an alternative to fossil resources to reduce environmental impact including emission of anthropogenic carbon dioxide [2]. Lignin is one of the main components of woody biomass, and the worldwide production of technical lignins as a by-product from chemical pulping processes stands at approximately 50 million t/yr [3]. It is merely used as fuel to recover energy in conventional pulping industry. However, lignin has been reported to have potential as a raw material for production of chemicals and materials [4]. It is necessary to develop highly value-added, functional materials from technical lignins if one is to establish an economically-feasible, biomass refinery process that enables sustainable use of woody biomass.

We have already reported the conversions of acetic acid lignin (AL), obtained by the atmospheric acetic acid pulping as an organosolv pulping process, to functional materials such as amphiphiles, carbon fibers, activated carbon fibers, and a hot-melt type of adhesive [5-7]. The AL-derived amphiphiles prepared with diepoxy type polyethylene glycol (PEGDE) showed depression of water surface tension and clear critical micelle concentration (CMC), suggesting their usefulness as a surfactant. A surfactant of high performance was obtained by derivatizing AL with mono-epoxy type polyethylene glycol (EPEG) [1]. In this study, these modification procedures of AL were applied to other technical lignins to confirm that functional amphiphiles can be prepared from any types of technical lignin. In addition, a non-ionic surfactant with polyethylene glycol glycidyl ether, which is commercially available as DAEO, was introduced to technical lignins to improve surface activity of amphiphilic lignin derivatives. Dispersion of the amphiphilic lignin derivatives were estimated by measuring dispersion of gypsum pastes made of the derivatives and calcined gypsum, one of cement ingredients. 


\section{EXPERIMENTAL}

\section{Materials}

Acetic acid lignin (AL) was recovered as a water-insoluble precipitate from spent liquor of the atmospheric acetic acid pulping of birch wood [8]. Indulin-AT and SANPEARL CP (Nippon Paper Chemicals Co. Ltd., Tokyo, Japan) were used as kraft lignin (KL) and lignosufonate (LS), respectively.

PEGDEs having different degree of polymerization of PEG moiety were obtained from Nagase ChemteX Corporation, Osaka, Japan. Chemical structures of PEGDEs are depicted as series A in Figure 1. Mono-epoxide polyethylene glycol (EPEG) was prepared from PEGDE by blocking an epoxide group at one end, according to a previous paper [1]. Other chemicals with reagent grade were purchased from a chemical company (Wako Pure Chemical Industries, Ltd, Osaka, Japan.) All chemicals were used as received.

\section{Preparation of Lignin Amphiphiles}

Lignin was dissolved in $1 \mathrm{M} \mathrm{NaOH}$ solution, and the resulting solution $(0.1 \mathrm{~g} / \mathrm{mL})$ was allowed to equilibrate with continuous stirring under air atmosphere for $24 \mathrm{~h}$ at room temperature. A prescribed amount of PEGDE, EPEG, and DAEO each was added to the lignin alkaline solution and the mixture was stirred for $2 \mathrm{~h}$ at $70{ }^{\circ} \mathrm{C}$. The reaction mixture was acidified with acetic acid to $\mathrm{pH} 4$, and remaining PEGs and low molecular weight fractions were removed by ultrafiltration (cutoff = 1000 Da). Amphiphilic lignin derivatives were recovered by lyophilization.

Weight ratios of PEG component in amphiphilic lignin derivatives were determined by the modified Morgan method [1, 9, 10].

\section{Measurement of Surface Tension}


Surface tension measurements were carried out by the ring method using a $\mathrm{Du}$ Nouy tensiometer [11]. Deionized water (electrical resistivity $=18.2 \mathrm{M} \Omega \cdot \mathrm{cm}^{-1}$ ) was used in this measurement. Surface tension was measured 6-10 min after the sample addition into a measurement dish. Measurements were performed in triplicate, and the average values were calculated. Critical micelle concentration (CMC) was determined at the discontinuity point on the surface tension vs. logarithm of concentration plot. Time course of the surface tension was measured on a CBVP-Z automatic tensiometer (Kyowa Interface Science Co. Ltd., Saitama, Japan).

\section{Measurement of Dispersibility for Gypsum}

Dispersibility of lignin derivatives for gypsum paste was measured according to previous reports [12-13] as follows. A lignin derivative was dissolved in $68 \mathrm{~mL}$ water at 20 ${ }^{\circ} \mathrm{C}$. A 125 g of gypsum (calcined gypsum purchased from Yoshino Gypsum Co., Japan) was added to the solution. The gypsum suspension was stirred with a mechanical stirrer for 30 sec to yield a paste, and was poured into a plastic cylinder $(50 \mathrm{~mm}$ in diameter, $50 \mathrm{~mm}$ in height), the bottom part of which was placed on a glass plate. After $70 \mathrm{sec}$, the cylinder was removed to render the gypsum paste spread on the glass. The final diameter $\varphi_{\text {final }}$ of the gypsum paste was measured. This experiment was repeated at least three times. The average value was used to calculate the flow value, using the following equation [14].

$$
\text { Flowvalue }(\%)=\frac{\phi_{\text {final }}-\phi_{\text {in }}}{\phi_{\text {in }}} \times 100
$$

where $\varphi_{\text {final }}$ is the final diameter of gypsum, and $\varphi_{\text {in }}$ is the initial diameter (50 mm).

The flow value of gypsum without any additives was 96.4.

\section{RESULTS AND DISCCUSION}




\section{Preparation of Amphiphilic KL Derivatives}

KL was converted to amphiphilic derivatives by the same procedure of polyoxyethylation with PEGDE and EPEG as AL derivatization. However, the minimum charge ratios of PEGDE and EPEG to prepare the water-soluble KL derivative were 1.5 times as much as that to prepare the water-soluble AL counterpart (Table 1). KL derivatives are soluble in organic solvents, such as methanol, ethanol, acetic acid, chloroform and pyridine in addition to water. Thus, KL derivatives are amphiphiles.

The contents of ethylene oxide (EO) repeating unit in lignin derivatives were determined by the modified Morgan method $[1,9,10]$. The EO contents of KL derivatives were smaller than those of AL derivatives, in spite of the increased (1.5-fold) charges of PEGDE and EPEG for KL derivatives (Table 1). These differences were at least partly caused by the differences in reactivity and amount of hydroxyl groups, which are under investigation.

HLB value was calculated by the Griffin's equation [15] based on the weight ratio of PEG moiety to KL moiety in KL derivatives. The HLB values of PEGDE-KL and EPEG-KL were ranged from 11 to 15 (Table 1). These values were very similar to those of AL derivatives. Therefore, amphiphilic KL derivatives were also expected to be promising surfactants for an oil-in-water (O/W) type emulsifiers and detergents.

\section{Surface Activity of Amphiphilic KL Derivatives}

To examine feasibility of amphiphilic KL derivatives as a surfactant, the surface tension of water in the presence of the derivatives was measured by the ring method [11] on a Du Nouy tensiometer. Although PEG didn’t significantly depressed water surface tension [1], amphiphilic KL derivatives remarkably depressed the water surface tension as well as AL derivatives. When water surface tensions in $0.1 \mathrm{~g} / \mathrm{mL}$ of lignin derivative solution were 
compared, EPEG-KL showed minimum value (Table 2), suggesting the derivatization with monoepoxylated PEG (EPEG) was more effective to prepare a surfactant than that with diepoxylated PEG (PEGDE). These results suggest that PEG introduction into technical lignins is a very useful and facile derivatization to obtain non-ionic surfactants.

\section{Improvement of Surface Activity of Amphiphilic Lignin Derivatives with DAEO}

As shown in previous sections, amphiphilic lignin derivatives were successfully prepared from hydrophobic technical lignins by the introduction of hydrophilic PEGs. Lignin and PEG had no significant high surface activity.

We expected that the activity of lignin derivatives could be improved by introduction of long alkyl chain into PEG moiety. DAEO (Figure 1) is a commercially available polymer with long alkyl chain, which shows surface activity. We thus investigated effect of alkyl chain on the surface activity of amphiphilic derivatives prepared from technical lignins (AL, KL and LS) and DAEO.

$\mathrm{AL}$ and $\mathrm{KL}$ were converted to water-soluble derivatives by the addition of $3 \mathrm{~g}$ and 5 $\mathrm{g}$ of DAEO to $1 \mathrm{~g}$ of lignins, respectively. PEG contents and HLB value are shown in Table 3. HLB values of both lignin derivatives were similar to PEGDE- and EPEG-derivatives.

The DAEO-lignin derivatives revealed better surface activity than EPEGderivatives. In particular, the CMC values were much smaller. The difference in CMC between DAEO- and EPEG-derivatives was two orders of magnitude, as shown in Figure 2. Thus, surface activity of lignin derivatives was easily and drastically improved by the use of DAEO; the long alkyl chain attached PEG moiety significantly contributes to better surface activity of the lignin derivatives. Therefore, it is expected that the surface activity of LS can be improved more significantly by introduction of DAEO into LS, because LS is a well-known, anionic surfactant and used as a cement dispersant. 
DAEO-LS preparations were produced by varying charge ratio of DAEO to LS, from 0.005 to 1 (g/g) under alkaline conditions. A LS solution indicated $40 \mathrm{mN} / \mathrm{m}$ of surface tension at $0.20 \mathrm{~g} / \mathrm{mL}$ (Fig. 3). By contrast, DAEO-LS solution (charge ratio: 0.005 $\mathrm{g} / \mathrm{g}$ ) achieved $40 \mathrm{mN} / \mathrm{m}$ of surface tension only at the concentration of $0.0027 \mathrm{~g} / \mathrm{mL}$. Figure 4 shows that the required concentration of DAEO-LS solution attained $40 \mathrm{mN} / \mathrm{m}$ of surface tension decreases as the charge ratio of DAEO to LS increases. Finally, the charge ratio of 0.5 showed the lowest concentration. The CMC of DAEO-LS (0.5) was one digit smaller than that of DAEO itself, although the surface tension at the CMC of the DAEO-LS (35 $\mathrm{mN} / \mathrm{m}$ ) was higher only slightly than that of DAEO (31 mN/m).

These results obviously suggest that an introduction of DAEO even in small amount dramatically improved surface activity of LS.

\section{Time Course of the Surface Tension after the Addition of Lignin Derivatives}

We have already shown that surface tension of amphiphilic lignin derivative aqueous solution gradually decreased with time, and finally reached at a constant value, like other polymeric surfactants $[1,16]$. Therefore, time courses of surface tension in the presence of DAEO-lignin derivatives were measured by using an automatic tensiometer to obtain precise surface tension. Herein the time courses of surface tension of LS, DAEO-AL(3), DAEO-KL(5), and DAEO-LS(1) aqueous solution at CMC estimated by Du Nouy tensiometer were monitored up to $10^{4}$ sec.

Figure 5 also gave additional evidence that the surface tensions of LS and DAEO-lignin derivative series gradually decreased with time. Although the surface tension of LS aqueous solution did not reach a constant value even after $10^{4}$ sec, it decreased up to 
$38 \mathrm{mN} / \mathrm{m}$. On the other hand, the DAEO series indicated significant reduction after $10^{2} \mathrm{sec}$, and reached at $30 \mathrm{mN} / \mathrm{m}$ or less.

\section{Dispersibility of Amphiphilic Lignin Derivatives}

LS is actually used as a dispersant of cement. DAEO-LS would be expected to be a superior dispersant because it shows much better surface activity than LS. In this study, the dispersibilities of not only DAEO-LS and LS but also other amphiphilic lignin derivatives for gypsum paste were evaluated. The results were shown in Figure 6, where the larger flow value, the better dispersity.

Figure 6 clearly indicated that gypsum paste prepared from DAEO-LS derivatives gave higher dispersity than that prepared from LS. The flow value of DAEO-LS (0.05) was 1.3 times as much as that of LS. Interestingly, DAEO-LS (0.05) was found to be a better dispersant than DAEO-LS (0.5) in spite of its lower PEG content. Similarly, gypsum pastes prepared from DAEO-KL and DAEO-AL showed comparable dispersity to that prepared from LS, suggesting that DAEO-lignin derivatives are promising cement dispersants.

Surprisingly enough, EPEG-AL also showed higher dispersity than LS, while the flow value of PEGDE-AL was lower than blank. From visual observation, PEGDE-AL did not seem to disperse gypsum particles, but to coagulate them. This result can partly be explained by the difference in the structure of lignin derivatives. EPEG is a monoepoxide compound while PEGDE is a diepoxide. Bifunctional epoxides, PEGDE, can thereby act as a cross-linker of AL molecules [17], which may restrict the segmental movement of the hydrophilic domain of the resulting derivatives [1]. If this is the case, PEGDE-AL molecules would not allow the gypsum particles to form a stable dispersed structure in water, but aggregate structure. 


\section{CONCLUSIONS}

This study demonstrated that introduction of PEGDE and EPEG into AL, a facile method to convert it to amphiphiles of high performance, was applicable to other technical lignins. Its application to KL gave amphiphiles of high surface activity. This means KL plays a hydrophobic part in the amphiphiles just like AL.

An introduction of DAEO into technical lignins dramatically improved surface activity. In particular, CMCs of the DAEO-derivatives were 2-4 orders of magnitude lower than those of EPEG-derivatives. Furthermore, the DAEO introduction significantly improved surface activity and gypsum dispersity of LS. The improvement of gypsum dispersity was also observed for EPEG-AL.

Therefore, it is concluded that all technical lignins used in this study can be converted to promising dispersants for cement production by one step modification with epoxylated PEG analogues.

\section{ACKNOWLEDGEMENTS}

Part of this work was supported by Ministry of Agriculture, Forestry and Fisheries of Japan (BM-D1321).

\section{REFERENCES}

1. Homma, H.; Kubo, S.; Yamada, T.; Matsushita, Y.; Uraki, Y. Preparation and Characterization of Amphiphilic Lignin Derivatives as Surfactants. J. Wood Chem. Technol. 2008, 28(4), 270-282.

2. Boman, Ulf R.; Turbbull, Jane H. Integrated biomass energy systems and emissions of carbon dioxide. Biomass Bioenergy. 1997, 13(6), 333-343. 
3. El-Wakil, N. A. Use of lignin strengthened with modified wheat gluten in biodegradable composites. J. Appl. Polym. Sci. 2009, 113(2), 793-801.

4. Goldstein, I. S. Potential for converting wood into plastics. Sci. 1975, 189(4206), $847-52$.

5. Kubo, S.; Uraki, Y.; Sano, Y. Preparation of carbon fibers from softwood lignin by atmospheric acetic acid pulping. Carbon. 1998, 36 (7-8), 1119-1124.

6. Uraki, Yasumitsu; Taniwatashi, Ryo; Kubo, Satoshi; Sano, Yoshihiro. Activated carbon sheet prepared from softwood acetic acid lignin. J. Wood Sci. 2000, 46(1), 52-58.

7. Uraki, Yasumitsu; Ishikawa, Naoya; Nishida, Mitsukuni; Sano, Yoshihiro. Preparation of amphiphilic lignin derivative as a cellulase stabilizer. J. Wood Sci. 2001, 47(4), 301-307.

8. Uraki, Y.; Sano, Y.; Sasaya, T. Cooking of hardwoods with organosolv pulping in aqueous acetic acid containing sulfuric acid at atmospheric pressure. Jpn TAPPI $J$. 1991, 45(9), 1018-1024.

9. Morgan P.W. Determination of ethers and esters of ethylene glycol: a modified alkoxyl analysis. Ind. Eng. Chem. Anal. Ed. 1946, 18, 500-504.

10. Siggia, S.; Starke, A.C.; Stahl, C.R. Determination of oxyalkylene groups: in glycols and glycol and polyglycol ethers and esters. J. Chromatogr. 1958, 30, 115-116.

11. Du N.; Lecomte P. A new apparatus for measuring surface tension. J. Gen. Physiol. 1919, 1, 521-524.

12. Nishimori, Y.; Ishitoku, H.; Kawamura, M. 1997, M. Jpn. Pat. 2696303.

13. Matsushita, Y.; Yasuda, S. Preparation and evaluation of lignosulfonates as a dispersant for gypsum paste from acid hydrolysis lignin. Biores. Technol. 2004, 96(4), 465-470.

14. Nadif, A.; Hunkeler, D.; Kauper, P. Sulfur-free lignins from alkaline pulping tested in mortar for use as mortar additives. Biores Technol. 2002, 84(1), 49-55. 
15. Griffin, W. C. Calculation of "HLB" values of nonionic surfactants. Am. Perfum. Essent. Oil Rev. 1955, 65(5), 26-9.

16. Persson, B.; Nilsson, S.; Bergman, R. Dynamic surface tension of dilute aqueous solutions of nonionic cellulose derivatives in relation to other macromolecular characterization parameters. J. Colloid Interface Sci. 1999, 218(2), 433-441.

17. Nishida, M.; Uraki, Y.; Sano, Y. Lignin gel with unique swelling property. Biores. Technol. 2003, 88(1), 81-83. 


\section{Figure captions}

Figure 1. Chemical structure of polyethylene glycol diglycidylether (PEGDE, A), ethoxy (2-hydroxy)propoxy polyethylene glycol glycidylether (EPEG, B) and dodecyloxy-polyethylene glycol glycidyl ether (DAEO, C).

Figure 2. Surface tension-concentration isotherms for EPEG-AL, DAEO-AL, EPEG-KL, and DAEO-KL. A) $\diamond$, EPEG-AL(13,4); •, DAEO-AL(3); B) •, EPEG-KL(13,6); o, DAEO-KL(5).

Figure 3. Surface tension-concentrations isotherms for LS, DAEO, and DAEO-LS. ', LS; o, DAEO-LS(0.005); $\triangle$, DAEO; •, DAEO-LS (0.5).

Figure 4. Concentration of DAEO-LS at $40 \mathrm{mN} / \mathrm{m}$ of surface tension.

Figure 5. Time course of the water surface tension after the addition of LS, DAEO-AL (3), DAEO-KL (5), and DAEO-LS (1). The value in parenthesis is a charge ratio of epoxy compound (g) to LS (g).

Figure 6. Dispersibility of amphiphilic lignin derivatives and LS. The amphiphilic lignin derivative was added to calcined gypsum in proportion of 0.01 part to 1 . Blank stands for the calcined gypsum only.

Table 1. Chemical characteristics of PEGDE-AL, EPEG-AL, PEGDE-KL, and EPEG-KL.

Table 2. Surface tensions of PEGDE-AL, EPEG-AL, PEGDE-KL, and EPEG-KL at 0.1 
$\mathrm{g} / \mathrm{mL}$.

Table 3. Chemical characteristics of DAEO series.

A)

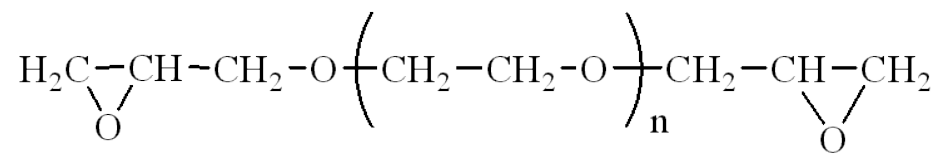

B) $\mathrm{CH}_{3}-\mathrm{CH}_{2}-\mathrm{O}-\mathrm{CH}_{2}-\underset{\mathrm{OH}}{\mathrm{CH}}-\mathrm{CH}_{2}-\mathrm{O}-\left(\mathrm{CH}_{2}-\mathrm{CH}_{2}-\mathrm{O}\right)_{\mathrm{n}} \mathrm{CH}_{2}-\mathrm{CH}_{\mathrm{O}}^{\mathrm{H}}-\mathrm{CH}_{2}$

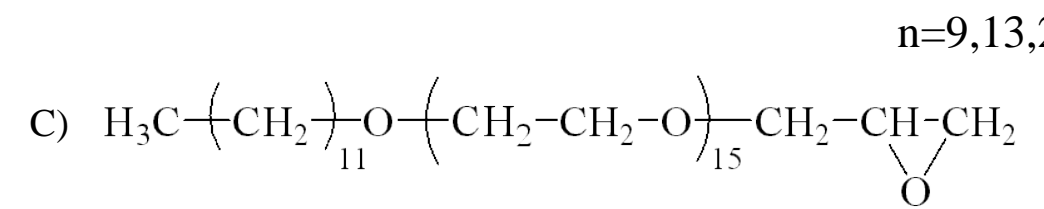

Figure 1. Chemical structure of polyethylene glycol diglycidylether (PEGDE, A), ethoxy (2-hydroxy)propoxy polyethylene glycol glycidylether (EPEG, B) and dodecyloxy-polyethylene glycol glycidyl ether (DAEO, C).

A)

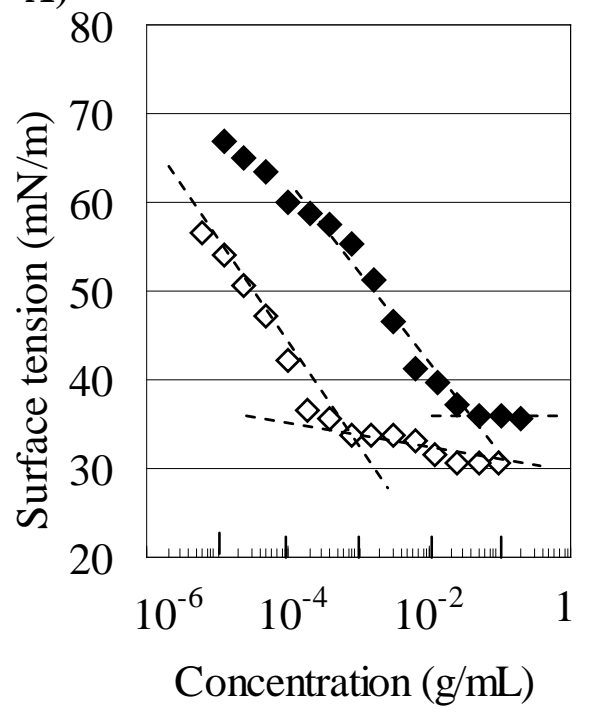

B)

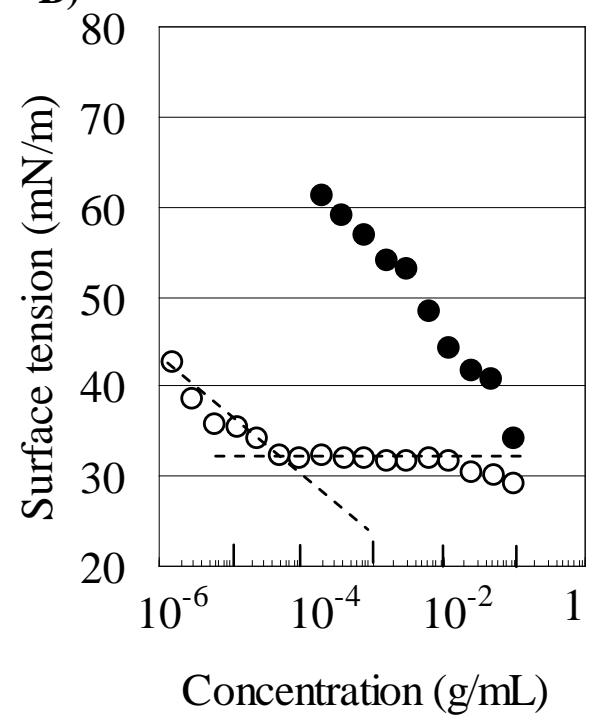

Figure 2. Surface tension-concentration isotherms for EPEG-AL, DAEO-AL, EPEG-KL, and DAEO-KL. A) $\diamond$, EPEG-AL(13,4); • DAEO-AL(3); B) •, EPEG$\mathrm{KL}(13,6)$; o, DAEO-KL(5). 


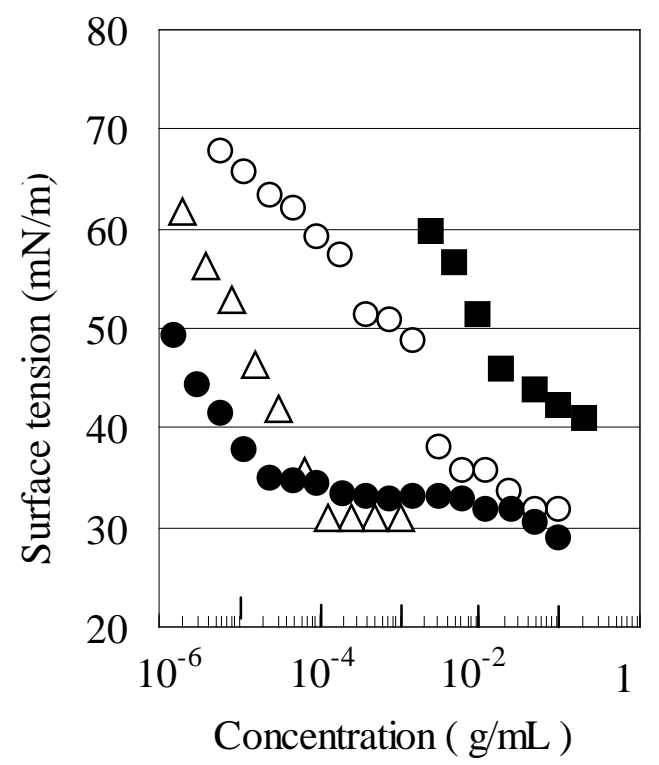

Figure 3. Surface tension-concentrations isotherms for LS, DAEO, and DAEO-LS. •, LS; o, DAEO-LS(0.005); $\Delta$, DAEO; •, DAEOLS (0.5).

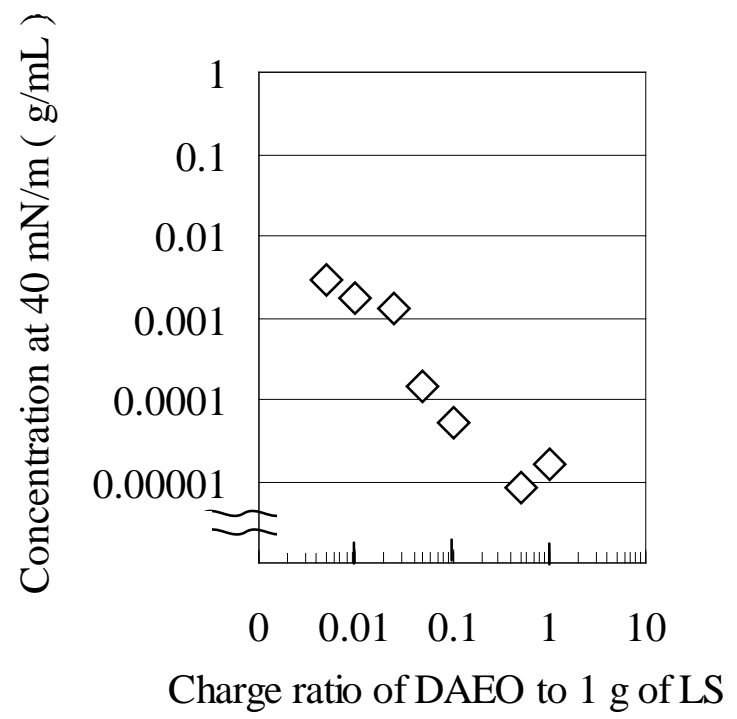

Figure 4. Concentration of DAEO-LS at $40 \mathrm{mN} / \mathrm{m}$ of surface tension. 


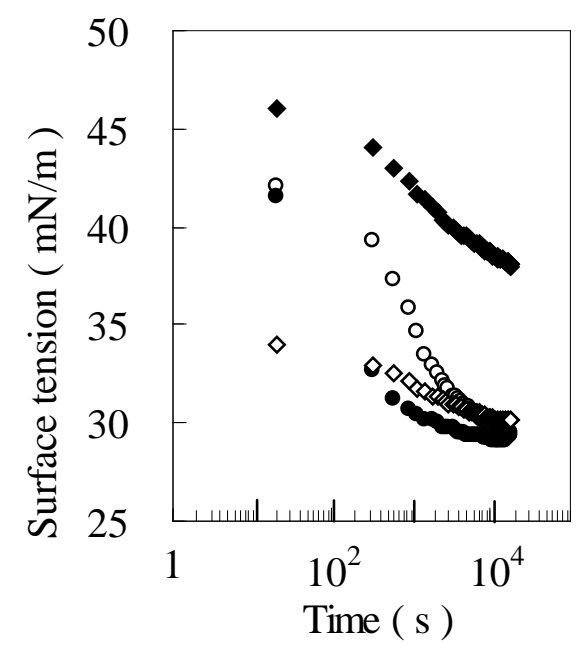

Figure 5. Time course of the water surface tension after the addition of LS, DAEO-AL (3), DAEO-KL (5), and DAEO-LS (1). The value in parenthesis is a charge ratio of epoxy compound (g) to LS (g). o, DAEO-LS(1); •, DAEO-KL(5); $\diamond$, DAEO-AL(3); $\bullet$, LS.

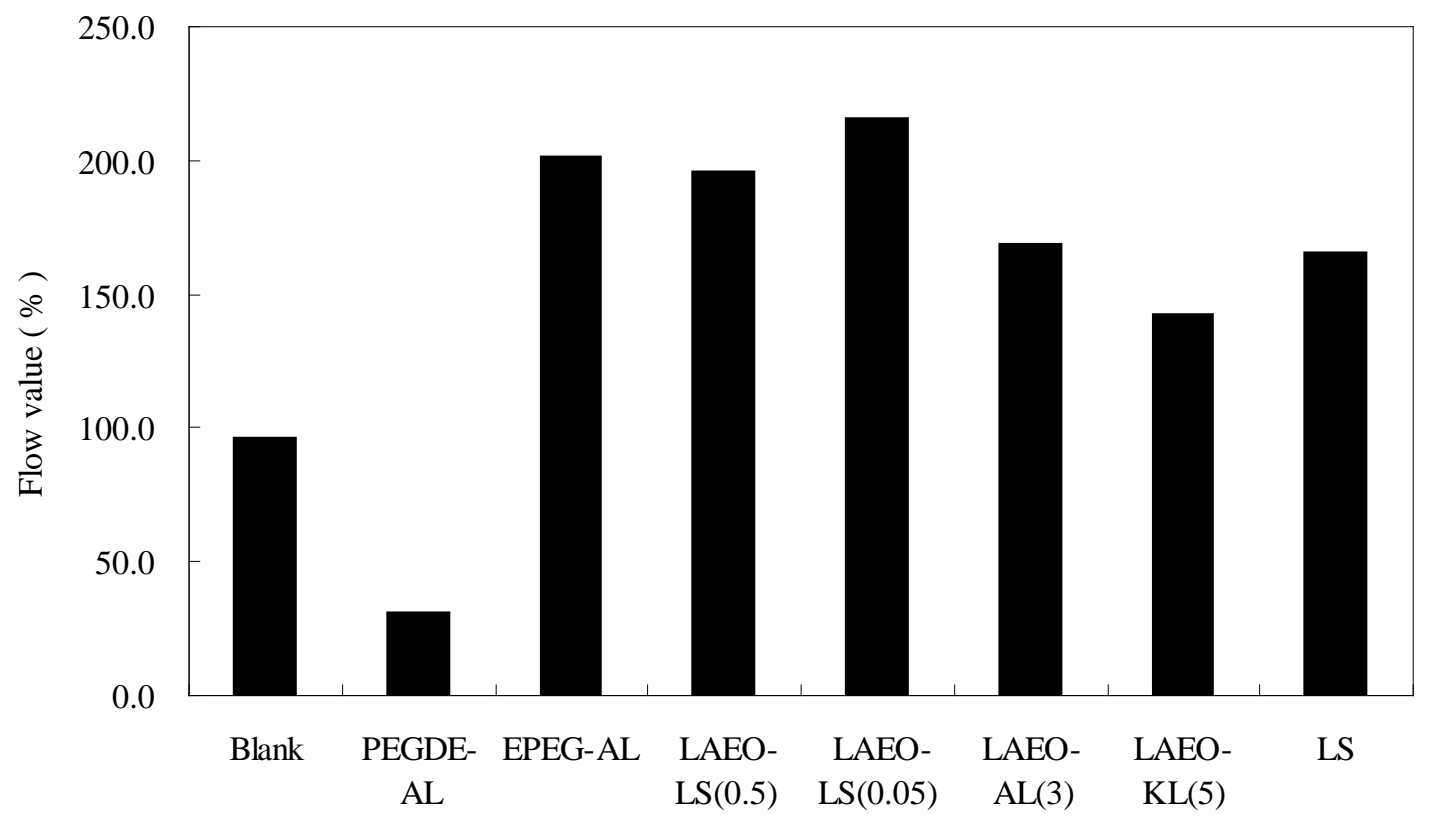

Figure 6. Dispersibility of amphiphilic lignin derivatives and LS. The amphiphilic lignin derivative was added to calcined gypsum in proportion of 0.01 part to 1 . Blank stands for the calcined gypsum only. 
Table 1. Chemical characteristics of PEGDE-AL, EPEG-AL, PEGDE-KL, and EPEG-KL.

\begin{tabular}{lccccc}
\hline & EO (\%) & HLB & $\begin{array}{c}\text { Surface } \\
\text { tension at } \\
\text { CMC (mN/m) }\end{array}$ & $\begin{array}{c}\text { CMC } \\
(\mathrm{g} / \mathrm{mL})\end{array}$ \\
\hline PEGDE-AL $(13,1)$ & 61.2 & 12.2 & 45.0 & $6.3 \times 10^{-3}$ \\
PEGDE-AL $(13,2)$ & 68.9 & 13.8 & 41.0 & $2.5 \times 10^{-2}$ \\
\hline EPEG-AL & $(13,2)$ & 63.8 & 12.8 & 42.0 & $3.2 \times 10^{-3}$ \\
EPEG-AL & $(13,4)$ & 72.3 & 14.5 & 36.0 & $5.0 \times 10^{-2}$ \\
\hline PEGDE-KL $(13,1.5)$ & 56.8 & 11.4 & - & - \\
PEGDE-KL $(13,3)$ & 68.4 & 13.7 & 44.0 & $2.5 \times 10^{-4}$ \\
\hline EPEG-KL & $(13,3)$ & 62.8 & 12.6 & - & - \\
EPEG-KL & $(13,6)$ & 76.3 & 15.3 & - & - \\
\hline
\end{tabular}

The first value in parenthesis is the number of EO repeating unit of the used epoxy compounds, and the second one is a charge ratio of epoxy compound to lignin. EO (\%) is molar ratio of EO unit to lignin. HLB is hydrophile-lipophile balance calculated by the Griffin's equation.

Table 2. Surface tensions of PEGDE-AL, EPEG-AL, PEGDE-KL, and EPEG-KL at $0.1 \mathrm{~g} / \mathrm{mL}$.

\begin{tabular}{lc}
\hline & $\begin{array}{c}\text { Surface tension } \\
(\mathrm{mN} / \mathrm{m})\end{array}$ \\
\hline PEGDE-AL $(13,1)$ & 40 \\
PEGDE-AL $(13,2)$ & 39 \\
\hline EPEG-AL $(13,2)$ & 36 \\
EPEG-AL $(13,4)$ & 36 \\
\hline PEGDE-KL $(13,1.5)$ & 43 \\
PEGDE-KL $(13,3)$ & 43 \\
\hline EPEG-KL $\quad(13,3)$ & 40 \\
EPEG-KL $(13,6)$ & 34 \\
\hline
\end{tabular}


Table 3. Chemical characteristics of DAEO series.

\begin{tabular}{lccccc}
\hline & EO ( \% ) & HLB & $\begin{array}{c}\text { Surface } \\
\text { tension at 0.1 } \\
\mathrm{g} / \mathrm{mL} \\
(\mathrm{mN} / \mathrm{m})\end{array}$ & $\begin{array}{c}\text { Surface } \\
\text { tension at } \\
\text { CMC (mN/m) }\end{array}$ & $\begin{array}{c}\text { CMC } \\
(\mathrm{g} / \mathrm{mL})\end{array}$ \\
\hline DAEO-AL (3) & 63.0 & 12.6 & 42 & 34 & $7.8 \times 10^{-3}$ \\
DAEO-AL (6) & 68.4 & 13.7 & 34 & 34 & $2.0 \times 10^{-4}$ \\
\hline DAEO-KL (5) & 65.4 & 13.1 & 32 & 32 & $5.0 \times 10^{-5}$ \\
DAEO-KL (10) & 70.5 & 14.1 & 31 & 31 & $4.8 \times 10^{-5}$ \\
\hline DAEO-LS (1) & 63.6 & 12.7 & 36 & 36 & $5.0 \times 10^{-5}$ \\
DAEO-LS (0.5) & 60.1 & 12.0 & 34 & 35 & $2.4 \times 10^{-5}$ \\
DAEO-LS (0.1) & 51.0 & 10.2 & 37 & 34 & $3.9 \times 10^{-4}$ \\
DAEO-LS (0.05) & 43.8 & 8.8 & 43 & n.d. & n.d. \\
DAEO-LS (0.025) & 43.2 & 8.6 & 46 & n.d. & n.d. \\
DAEO-LS (0.01) & 43.1 & 8.6 & 55 & n.d. & n.d. \\
DAEO-LS (0.005) & 41.7 & 8.3 & 59 & n.d. & n.d. \\
\hline
\end{tabular}

The value in parenthesis is a charge ratio of DAEO to lignin. EO (\%) is molar ratio of EO unit to lignin. HLB is hydrophile-lipophile balance calculated by the Griffin's equation. N. d. means non-detectable. 